\title{
A new benzimidazole and benzothiazole derivatives containing phenoxy moiety with herbicidal activity
}

\author{
Nowe pochodne benzimidazolu i benzotiazolu \\ z ugrupowaniem fenoksylowym o aktywności herbicydowej
}

Zbigniew Ochal ${ }^{1}$, Maria Krawczyk ${ }^{2}$

Summary

A series of new substituted benzimidazole and benzothiazole containing phenoxy moiety and halogenomethylsulfonyl groups were synthesized. Biological activity of synthesized compounds was evaluated in screening tests. The $(R)$ enantiomers of benzothiazole derivatives containing difluoromethylsulfonyl groups in the benzene ring and phenoxy moiety in the imidazole sceleton exhibited good herbicidal activity.

Key words: benzimidazole, benzothiazole derivatives, herbicides, screening

\section{Streszczenie}

Zsyntezowano nowe pochodne benzoimidazolu i benzotiazolu zawierające w pozycji 2 ugrupowania fenoksyetylowe, a w pierścieniu benzenowym grupy fluorometylosulfonylowe. Oceniono aktywność biologiczną związków w doświadczeniach skryningowych. Najwyższą aktywność chwastobójczą wykazywały enancjomery $(R)$ pochodnych benzotiazolu zawierające w pierścieniu benzenowym ugrupowanie difluorometylosulfonylowe, a w pierścieniu imidazolowym grupy fenoksyetylowe.

Słowa kluczowe: pochodne benzimidazolu, pochodne benzotiazolu, aktywność chwastobójcza, skryning

\footnotetext{
Politechnika Warszawska

Wydział Chemiczny

Noakowskiego 3, 00-664 Warszawa

ochal@ch.pw.edu.pl

${ }^{2}$ Instytut Przemysłu Organicznego

Annopol 6, 03-236 Warszawa
} 


\section{Wstęp / Introduction}

W ramach prac poszukiwawczych nad nowymi środkami ochrony roślin podjęto badania nad otrzymywaniem nowych pochodnych benzimidazolu i benzotiazolu zawierających w pozycji 2 ugrupowania fenoksyetylowe, a w pierścieniu benzenowym grupy halogenometylosulfonylowe. Wybór podyktowany był tym, że pochodne benzimidazolu i benzotiazolu są związkami aktywnymi biologicznie i są stosowane jako agrochemikalia. Kwasy fenoksyalkilokarboksylowe i ich pochodne są znanymi herbicydami i regulatorami wzrostu roślin, stosowanymi powszechnie do zwalczania chwastów dwuliściennych w uprawach zbóż. Ugrupowania halogenometylosulfonylowe występujące w syntezowanych połączeniach nadawały $\mathrm{w}$ wielu przypadkach pochodnym aromatycznym interesującą aktywność pestycydową (Ochal i wsp. 1994). Do syntezy stosowano enancjomery $(R)$ kwasów fenoksypropionowych, odpowiedzialnych za aktywność herbicydową, uzyskując 2-fenoksyetylopochodne benzimidazolu i benzotiazolu również o konfiguracji $R$ $\mathrm{z}$ dobrymi nadmiarami enancjomerycznymi.

\section{Materiały i metody / Materials and methods}

\section{Synteza pochodnych benzimidazolu}

Kwasy (R)-fenoksypropionowe otrzymywano wychodząc $\mathrm{z}$ handlowego $(S)-(-)$-mleczanu etylu, który w reakcji z chlorkiem metylu przekształcano w ester - $(S)-2$ (metylosulfonyloksy)propionian etylu (Ochal i wsp. 2010). Ester ten poddawano następnie $\mathrm{w}$ środowisku zasadowym reakcji typu $\mathrm{S}_{\mathrm{N}} 2$ z podstawionymi fenolami, przebiegającej z inwersją konfiguracji. Uzyskano estry kwasów 2-fenoksypropionowych o konfiguracji $(R) \mathrm{z}$ wysokimi wydajnościami i dobrymi nadmiarami enancjomerycznymi. Produkty oczyszczano przez destylację pod zmniejszonym ciśnieniem. Syntezę kwasów $(R)-(+)-2$-fenoksypropionowych przedstawia rysunek 1 .

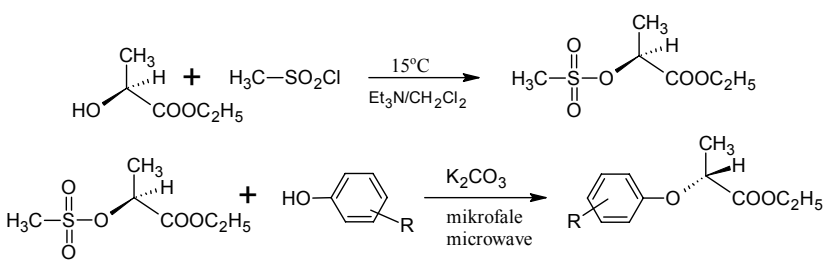

Rys. 1. Synteza estrów etylowych kwasów (R)-2-fenoksypropionowych

Fig. 1. Synthesis of $(R)$-2-phenoxypropionic acids ethyl esters

Estry te hydrolizowano do kwasów $(R)$-2-fenoksypropionowych stosując wodno-metanolowy roztwór wodorotlenku sodowego (rys. 2).

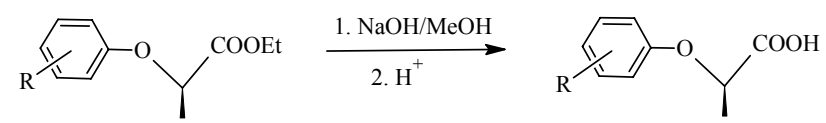

Rys. 2. Synteza kwasów $(R)$-2-fenoksypropionowych

Fig. 2. Synthesis of $(R)$-2-phenoxypropionic acids
Uzyskane kwasy stosowano do syntezy pochodnych benzimidazolu i benzotiazolu $\mathrm{w}$ reakcjach $\mathrm{z}$ pochodnymi aniliny. Cyklizację pochodnych benzimidazolu i benzotiazolu prowadzono $\mathrm{w}$ warunkach metody Phillipsa stosując 6N kwas chlorowodorowy (Ochal i wsp. 2012). Reakcje prowadzono w temperaturze $100^{\circ} \mathrm{C}$, w czasie od 2 do 8 godzin. Produkty wydzielano z wydajnościami od 65 do $96 \%$ (rys. 3 ).

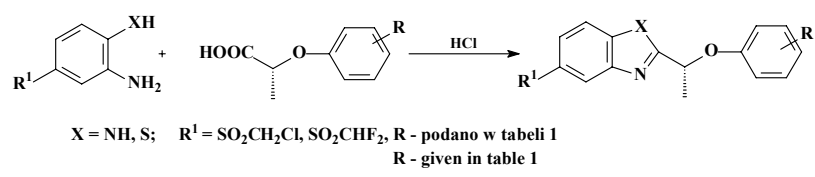

Rys. 3. Synteza pochodnych (R)-2-(1-fenoksyetylo)benzimidazolu i benzotiazolu

Fig. 3. Synthesis of (R)-2-(1-phenoxyethyl)benzimidazole and benzothiazole derivatives

Pochodną 4-chlorometylosulfonylo o-fenylenodiaminy otrzymano w wieloetapowej syntezie według sekwencji przemian, którą przedstawia rysunek 4.

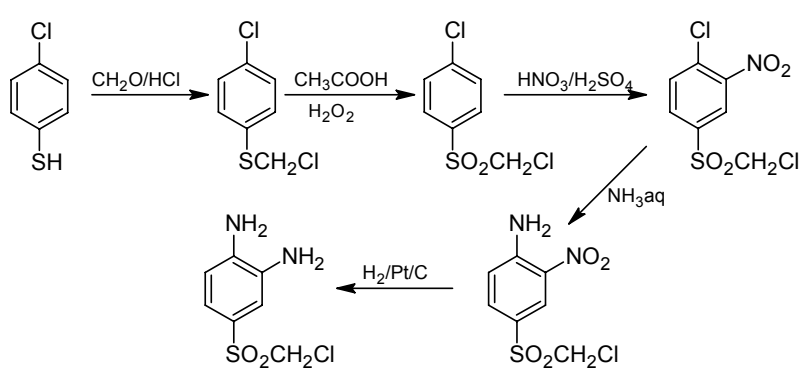

Rys. 4. Synteza 4-chlorometylosulfonylo-o-fenylenodiaminy

Fig. 4. Synthesis of 4-chloromethylsulfonyl-o-phenylenediamine

4-chlorotiofenol przekształcono w sulfid chlorometylowo-4-chlorofenylowy, który utleniono do sulfonu nadtlenkiem wodoru w kwasie octowym, a po znitrowaniu poddano reakcji typu $\mathrm{S}_{\mathrm{N}} \mathrm{Ar} \mathrm{z}$ amoniakiem. Uzyskaną pochodną 2-nitroaniliny zredukowano katalitycznie wodorem do stosowanej $\mathrm{w}$ syntezach benzoimidazoli diaminy (Ochal i wsp. 1994). 4-difluorometylosulfonylo-o-fenylenodiaminę syntezowano zgodnie ze schematem przedstawionym na rysunku 5.

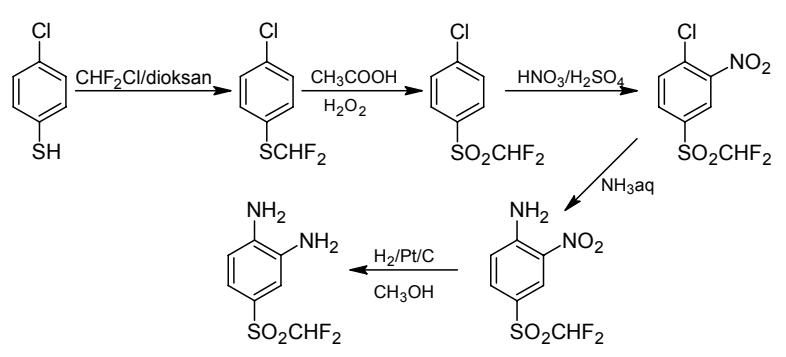

Rys. 5. Synteza 4-difluorometylosulfonylo-o-fenylenodiaminy Fig. 5. Synthesis of 4-difluoromethylsulfonyl-o-phenylenediamine 
Substratem był również 4-chlorotiofenol, który przekształcono $\mathrm{w}$ reakcji $\mathrm{z}$ chlorodifluorometanem $\mathrm{w}$ sulfid difluorometylowo-4-chlorofenylowy (Ochal i Trojanowska 2008). Dalsze postępowanie prowadzące do otrzymania 4-difluorometylosulfonylo-1,2-fenylodiaminy było analogiczne, jak w poprzedniej syntezie.

\section{Metody oceny dzialania chwastobójczego}

Aktywność chwastobójczą związków na różnych gatunkach chwastów badano $\mathrm{w}$ doświadczeniach wazonowych, w warunkach szklarniowych, w 4 powtórzeniach. Podłoże stanowiła gleba typu piasek gliniasty lekki, zawartość próchnicy 2,8\%, pH ( $\mathrm{HCl}) 6,7$.

Do wazonów płaskich o powierzchni $24 \times 30 \mathrm{~cm}$ i pojemności 31 wysiano po około 20 nasion chwastów każdego gatunku. Badane związki w postaci roztworów acetonowo-wodnych $\mathrm{z}$ dodatkiem środka powierzchniowego Tween $20(0,1 \% \mathrm{v} / \mathrm{v})$ aplikowano przedwschodowo lub powschodowo na rośliny w fazie $2-4$ liści, przy użyciu kabinowego opryskiwacza laboratoryjnego (TeeJet60, ciśnienie robocze $0,2 \mathrm{MPa}$, objętość cieczy roboczej $3001 /$ ha). Temperatura $\mathrm{w}$ czasie wegetacji wynosiła $20-25^{\circ} \mathrm{C}$, a długość dnia i nocy $16 / 8$ godzin. Ocenę działania chwastobójczego oceniano wizualnie po 18 dniach od aplikacji w procentach, przyjmując obiekt kontrolny jako 100.

\section{Wyniki i dyskusja / Results and discussion}

Wiele związków spośród nowych pochodnych halogenometylosulfonylobenzoazoli wykazało bardzo dobre działanie chwastobójcze. Najwyższą aktywność wykazywały enancjomery $(R)$ pochodnych benzotiazolu zawierające $\mathrm{w}$ pierścieniu benzenowym ugrupowanie difluorometylosulfonylowe, a w pierścieniu imidazolowym grupy fenoksyetylowe. Związki były pobierane zarówno poprzez liście, jak i korzenie chwastów, ale większość związków wykazywała lepsze działanie po aplikacji powschodowej (tab. 1).

Tabela 1. Aktywność chwastobójcza nowych pochodnych benzimidazolu i benzotiazolu

Table 1. Herbicidal activity of new benzimidazole and benzothiazole derivatives

\begin{tabular}{|c|c|c|c|c|c|c|c|c|c|c|c|c|c|c|c|c|}
\hline $\mathrm{R}^{1-}$ & & & ה/ $\mathrm{F}$ & 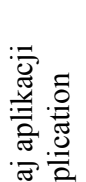 & 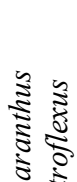 & 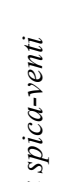 & $\begin{array}{l}Ð \\
\vdots \\
\vdots \\
\vdots \\
5 \\
\vdots\end{array}$ & $\begin{array}{l}2 \\
0 \\
0 \\
\vdots \\
1 \\
\vdots \\
2\end{array}$ & 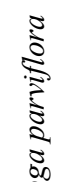 & 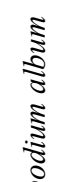 & 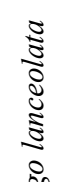 & 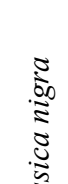 & 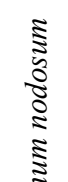 & 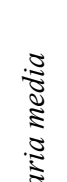 & 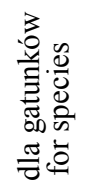 & 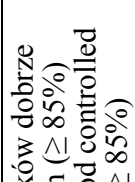 \\
\hline Związek & $\mathrm{X}$ & $\mathrm{R}^{1}$ & $\mathrm{R}$ & $\approx$ & & ब & ن & 2 & $\stackrel{i}{\tilde{\sigma}}$ & $\frac{\bar{\Xi}}{\tilde{U}}$ & $\frac{\tilde{\Xi}}{2}$ & & $\frac{2}{2}$ & $\tilde{\omega}$ & 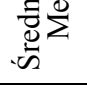 & 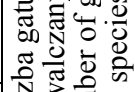 \\
\hline Compound & & & & & & & zniszc & enie c & $\begin{array}{l}\text { Iwastc } \\
{[\%}\end{array}$ & $N-\mathrm{s}$ & $\mathrm{dc}$ & trol & & & & 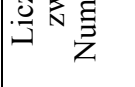 \\
\hline 160 & NUI & & & $\mathrm{g}$ & 100 & 20 & 40 & 40 & 100 & 100 & 40 & 100 & 40 & 70 & 65 & 4 \\
\hline & & & & $\mathrm{n}$ & 100 & 10 & 90 & 100 & 100 & 100 & 55 & 100 & 100 & 100 & 85 & 8 \\
\hline 16014 & NUI & $\mathrm{s} \Omega$ & 24 & g & 100 & 40 & 60 & 100 & 100 & 100 & 70 & 100 & 100 & 100 & 87 & 7 \\
\hline & & & & $\mathrm{n}$ & 100 & 30 & 55 & 100 & 100 & 100 & 100 & 100 & 100 & 100 & 89 & 8 \\
\hline 16015 & $\mathrm{NH}$ & $\mathrm{SO} C H \mathrm{H}$ & $2-\mathrm{CH}_{3}-$ & $\mathrm{g}$ & 100 & 20 & 55 & 100 & 70 & 100 & 100 & 100 & 40 & 100 & 79 & 6 \\
\hline & & 2 & $4-\mathrm{Cl}$ & $\mathrm{n}$ & 100 & 20 & 95 & 100 & 100 & 100 & 70 & 100 & 100 & 100 & 89 & 8 \\
\hline & $\mathrm{S}$ & & & g & 70 & 70 & 100 & 100 & 100 & 100 & 70 & 100 & 70 & 100 & 88 & 6 \\
\hline & & & & $\mathrm{n}$ & 100 & 20 & 100 & 100 & 100 & 100 & 40 & 100 & 100 & 100 & 86 & 8 \\
\hline 16083 & $\mathrm{~S}$ & & & g & 100 & 20 & 95 & 100 & 100 & 100 & 20 & 100 & 100 & 100 & 84 & 8 \\
\hline & & & & $\mathrm{n}$ & 100 & 95 & 100 & 100 & 100 & 100 & 100 & 100 & 100 & 100 & 100 & 10 \\
\hline $160+2$ & $\mathrm{C}$ & & & $\mathrm{g}$ & 100 & 20 & 55 & 100 & 70 & 70 & 20 & 100 & 20 & 70 & 63 & 3 \\
\hline & & & & $\mathrm{n}$ & 100 & 60 & 95 & 100 & 100 & 100 & 60 & 100 & 100 & 100 & 92 & 8 \\
\hline & $\mathrm{S}$ & & & $\mathrm{g}$ & 100 & 40 & 55 & 100 & 40 & 100 & 55 & 70 & 100 & 100 & 76 & 5 \\
\hline & & N & & $\mathrm{n}$ & 100 & 100 & 100 & 100 & 100 & 100 & 100 & 100 & 100 & 100 & 100 & 10 \\
\hline $\mathbf{A}$ & & & 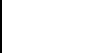 & $\mathrm{g}$ & 70 & 20 & 30 & 40 & 100 & 70 & 20 & 40 & 40 & 40 & 47 & 1 \\
\hline & & & & $\mathrm{n}$ & 100 & 45 & 100 & 100 & 100 & 100 & 65 & 100 & 100 & 100 & 92 & 8 \\
\hline
\end{tabular}

$\mathrm{g}$ - doglebowo - soil, $\mathrm{n}$ - dolistnie - foliar 
Najwyższą skuteczność chwastobójczą stwierdzono dla związków 16083 i 16085 ( $\left.\mathrm{R}=3,4-\mathrm{Cl}_{2}, \mathrm{Br}\right)$. W dawce $2 \mathrm{~kg} / \mathrm{ha}$, w zabiegu powschodowym całkowicie zniszczonych zostało 10 wszystkich testowanych gatunków chwastów, w tym: przytulia czepna (Galium aparine), mak polny (Papaver rhoeas), rdest kolankowaty (Polygonum nodosum), szarłat szorstki (Amaranthus retroflexus), babka lancetowata (Plantago lanceolata) i odpowiednio 8 i 5 gatunków w zabiegu doglebowym. Dobrą aktywność obydwa związki wykazały również wobec miotły zbożowej (Apera spica-venti). Ich skuteczność była wyższa niż wzorcowego środka handlowego MCPP, głównie z powodu absorpcji również poprzez glebę (mekoprop pobierany jest głównie przez liście i łodygi). Pozostałe związki dobrze zwalczały 8 spośród 10 zastosowanych gatunków chwastów, głównie dwuliściennych, w zabiegu nalistnym i około 4-6 gatunków w zabiegu doglebowym.

$\mathrm{W}$ dawce $1 \mathrm{~kg} / \mathrm{ha}$ w zabiegu dolistnym obydwa związki wykazały 100\% skuteczność wobec gatunków ruderalnych trudno zwalczanych, takich jak: łopian większy (Arctium lappa), szczaw kędzierzawy (Rumex crispus), palusznik krwawy (Digitaria sanguinalis), konopie siewne (Cannabis sativa), marchew zwyczajna (Daucus carota), rumian polny (Anthemis arvensis) (rys. 6). Działanie doglebowe było słabsze, na poziomie około $40 \%$ skuteczności. W danym zakresie testowanych roślin wymienione związki: 16083 i 16085 wykazały znacznie lepsze

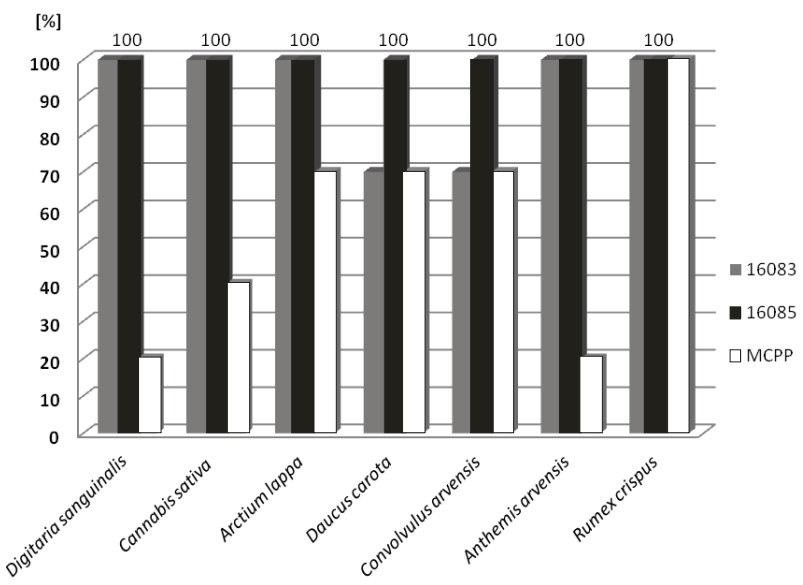

Rys. 6. Skuteczność chwastobójcza nowych zwiazków wobec gatunków chwastów trudno zwalczanych (dawka $1 \mathrm{~kg} / \mathrm{ha}$ )

Fig. 6. Herbicidal activity of new compounds against troublesome weed species (dose $1 \mathrm{~kg} / \mathrm{ha}$ )

działanie biologiczne niż zastosowany wzorcowy herbicyd - mekoprop, który zwalczał bardzo dobrze tylko 1 gatunek: szczaw kędzierzawy (Rumex crispus). Prace nad dalszym rozwojem tej grupy związków są kontynuowane.

\section{Literatura / References}

Ochal Z., Ejmocki Z., Ostrowski J. 1994. Synthesis of 1,2- and 5-substituted benzimidazole derivatives and their phytocidal activity. Organika - Prace Nauk. Inst. Przem. Org.: 1-8.

Ochal Z., Durka K., Banach Ł. 2010. Rapid and high yield synthesis of (R)-aryloxypropionic acid esters under microwave irradiation. Synth. Commun. 40: 3209-3213.

Ochal Z., Borys K., Korzyński M. 2012. Derivatives of phenyl tribromomethyl sulfone as novel compounds with potential pesticidal activity. Beilstein J. Org. Chem. 8: 259-265.

Ochal Z., Trojanowska A. 2008. Synthesis and transformation of 4-difluoromethylsulfonyl-2-nitrophenylsulfenylchloride into new compounds with promising pesticidal activity. Pol. J. Appl. Chem. 52 (3-4): 131-138. 